\title{
O SAGRADO É DIVINO, A RELIGIÃO É DOS HOMENS: TERRITÓRIOS CULTURAIS E FRONTEIRAS SIMBÓLICAS, A INTOLERÂNCIA RELIGIOSA NA CONTEMPORANEIDADE
}

\section{- AUREANICE DE MELLO CORRÊA ${ }^{1}$}

RESUMO: NO PRESENTE TEXTO OBJETIVAMOS APRESENTAR UMA REFLEXÃO INICIAL SOBRE 0 MOVIMENTO SOCIAL CRIADO NA CIDADE DO RIO DE JANEIRO NO ANO DE 2008 COMO REAC̦̃̃O A AÇ̃̃ES DE INTOLERÂNCIA RELIGIOSA. ESTAS AÇ̃̃ES OCORRIAM (E AINDA OCORREM) ESTABELECENDO DOIS CAMPOS DE FORÇAS: DE UM LADO TEMOS OS EVANGÉLICOS E DO OUTRO, DISTINTAS RELIGIÕES COMO ISLÂMICOS, JUDEUS, CATÓLICOS, HAREKRISHNAS, CIGANOS ENTRE OUTROS CAPITANEADOS POR CANDOMBLECISTAS E UMBANDISTAS. 0 ENCONTRO ENTRE ESTES GRUPOS REVELA UMA DISPUTA PELO ESPAÇO DA CIDADE COMO GARANTIA DA LIBERDADE DE PROFESSAR SEU CREDO TAL QUAL REZA A CONSTITUIC̦ÃO BRASILEIRA, SEMIOGRAFANDO COM ESTRATÉGIAS/TERRITORALIDADES ENGENDRADAS COLETIVAMENTE EM TERRITÓRIOS CULTURAIS NA CIDADE CONTEMPORÂNEA.

$\begin{array}{llll}\text { PALAVRAS-CHAVE: INTOLERANCIA RELIGIOSA, MOVIMENTO SOCIAL, } & \text { TERRITORIALIDADES }\end{array}$

\footnotetext{
A multiplicidade e a situações e espaços fragmentados entre fragmentação sob uma dinâmica pautada na elementos e acontecimentos singulares dialética (se explicam mutuamente, uma é aparentemente sem relação entre si, mas que se inerente à outra) são dois aspectos que estão encadeiam em ações pautadas pelas presentes como características das subjetividades agenciadas coletivamente. Em manifestações culturais neste começo de século XXI. outras palavras, estamos envolvidos por uma dinâmica processual, na qual a diversidade, a

Nesse sentido, se tornam distantes as aspirações de totalidade sinalizada pelo pensamento moderno. Estamos vivenciando simultaneidade e a inclusão estão presentes no cotidiano contemporâneo das cidades e dos seus cidadãos isto porque nada pode estar de fora, 
margeando, sem contato nesta nossa cultura urbana, midiática, das imagens e informatizada de começo de século, de começo de milênio. No processo em tela, mais do que nunca, o "outro" se tornou coprotagonista das ações humanas, porque hoje nada e nem ninguém pode ser excluído deste estilo de vida urbana.

Permanecendo na perspectiva em tela podemos pensar que uma das condições historicamente apresentadas pela cidade e/ou pelo estilo de vida urbano é a batalha/luta empreendida pela sobrevivência cotidiana. Sendo assim, aprofundando o sentido filosófico sobre o que define "luta", compreende-se que esta supõe a confrontação de forças antagônicas que em ultima instância encarnam a figura "de um" e "do outro", em concordância com Yory (2007, p.92) que, em sua análise do tema, afirma que "(...) ao fim das contas, mesmo quando na cidade temos mais de duas forças em conflito, estas se reduzem sempre a duas" 2 .Cabe então, diante da situação apresentada, estabelecer algumas indagações: $O$ que acontece no momento em que os dois antagonistas se enfrentam levando em conta que a fronteira que os separa - efetuada claramente por ações materiais e/ou imateriais, simbólicas - estabelece territórios distintos, mas que diante do processo de vida urbana contemporânea, estes passam a se entrecruzar, se superpor, a se interligar?

Nesse sentido, podemos ainda indagar: De que luta estamos falando? E, sobretudo, o que essa luta vai desencadear e para onde vai conduzir os citadinos/cidadãos na construção permanente de ações pautadas no ideal democrático?

Buscar sinais que venham contribuir para o esclarecimento dessas indagações é o esforço analítico que pretendemos empreender nesse texto, no qual vamos pensar sobre a questão da intolerância religiosa, especialmente na cidade do Rio de Janeiro e municípios que se situam na sua periferia imediata - componentes da sua área metropolitana - na luta pelo respeito religioso, por leis e políticas públicas como garantia da liberdade de culto e pela visibilidade no espaço da cidade, ações que se configuram como territorialidades, como estratégias de afirmação de identidades étnicas e que semiografam territórios encarnadores de práticas culturais distintas que se apartam, se aproximam, superpõem e se misturam entre cooperações e confrontos.

\section{Tolerância como valor moral e Intolerância religiosa como mal-estar da cultura contemporânea}

Voltaire - codinome pelo qual o filósofo francês que viveu no período que compreende o fim do século XVII e inicio do XVIII (1694 -1778) tornou conhecido François-Marie Arouet - vivenciou um tempoespaço de transição social, econômico e político ESPAÇO E CULTURA, UERJ, RJ, N. 31, P.125-138, JAN./JUN. DE 2012 http://www.e-publicacoes.uerj.br/index.php/espacoecultura/ 
europeu, e contribuiu com suas reflexões filosóficas para o aprofundamento da questão sobre a tolerância/intolerância especialmente enfocando a religiosa, que considerava como discórdia geradora do grande Mal da humanidade e, por conseguinte, das ações malsãs de intolerância. Tais idéias se expressam em suas palavras de repúdio à ação humana em questão, "(...) esta horrível discórdia, que dura há tantos séculos, constitui a lição bem expressiva que devemos perdoar-nos mutuamente os nossos erros; a discórdia é o grande mal do gênero humano e a intolerância seu único remédio" (1973,p.298).

Para Muller (2009), Voltaire - para além da análise da questão da intolerância religiosa contribuiu para a construção da Tolerância como valor moral e como defesa radical da condição humana, quando sinaliza que é necessário nos tolerarmos porque somos sujeitos ao erro. Somos fracos, inconsequentes e mutantes.

No caminho reflexivo do filósofo em tela, Voltaire (2005) considerava que era melhor o indivíduo ser subjugado às superstições de toda ordem do que viver sem um norte religioso, ou seja, ele entendia que o ser humano necessitava de um freio, de interditos que em determinadas situações do viver em sociedade encontrava na ação religiosa, no temor ao castigo divino, maior eficiência na resolução para suas questões do que as leis e sanções engendradas pela sociedade civil em prol de sua organização. No entanto, sinalizou para o perigo - com o qual concordamos - e apontou para a questão enfocada no presente texto - do não questionamento às próprias crenças, pois essa falta fomentava e ainda fomenta o fanatismo que por sua vez promove a destruição, a morte e a intolerância ao próximo, ao seu outro. Caminhando na direção acima apontada pela filosofia, nos dirigimos para a abordagem efetuada pelo geógrafo Sopher(1967) que em seus trabalhos afirma a ação religiosa como fenômeno cultural e estabelece, classificando-a em dois grandes grupos: as religiões étnicas e as religiões universalizantes.

As religiões étnicas estariam vinculadas às práticas culturais atreladas a um lugar específico, apresentando embargos para a assimilação tanto de suas crenças quanto de seus rituais e dificultando, assim, a sua disseminação. Em contrapartida, as universalizantes trariam em suas crenças dogmas e rituais imbuídos de sentidos comuns entre as suas práticas culturais, de modo que sua doutrina expresse as relações com Deus ou com os deuses de maneira apropriada para todos os indivíduos, facilitando a disseminação pelo mundo a partir do rompimento com o seu lugar de origem. Entre elas temos o Catolicismo, o Islamismo e o Budismo

O geógrafo em tela também pensa modelos geográficos de interação entre sistemas 
religiosos, observando as ações estratégicas e nos conduzindo, no presente texto, a considerálas como territorialidades, definidas em textos anteriores (CORRÊA, A M. 1997; 2004, entre outros), como ações/ estratégias engendradas pelo indivíduo ou grupo social para a constituição, defesa e manutenção do seu território cultural e que, na presente abordagem, serão consideradas como o jogo de poder vivenciado entre as minorias religiosas $\mathrm{e}$ domínios religiosos hegemônicos. Temos assim, três tipos que se intercalam, por vezes de forma superposta e por outras em separado no tempoespaço: a coexistência pacífica; a instabilidade e competição e, por fim, a intolerância e a exclusão.

No Brasil - focando na cidade do Rio de Janeiro a partir de ações de intolerância e exclusão, especialmente com o avanço do neopetencostalismo - passamos a assistir a um processo no qual estão envolvidos, concomitantemente, a coexistência pacífica, a instabilidade e a competição. Todavia, ressaltamos que, na visão de Sopher, a última situação contribui de forma positiva para a busca de equilíbrio, objetivo da primeira ação. Porém, apesar da consideração positiva do intelectual em questão, a intolerância religiosa no mundo contemporâneo vem atuando como uma das principais causas de desagregação social, ataques terroristas, guerras e disputa pelo espaço. A busca pela coexistência pacífica vem se tornando cada vez mais complexa, necessitando, mais do que nunca, da compreensão da diferença e o direito a esta, ou seja, especialmente no caso brasileiro e do objetivo de discussão do presente texto, da diferença de crença religiosa, e ao direito constitucional de liberdade religiosa.

Entretanto pensar a intolerância e a busca pela tolerância de forma ampla também implica a observação da extensão do seu raio de atuação, isto é, não circunscrevê-la apenas à diferença de crença religiosa. Nos dias de hoje a ação intolerante está vinculada à questão etnorracial em que vemos em destaque as diferenças identitárias individuais e coletivas, por exemplo, aquelas remetidas às ideias de "raça", "cor", gênero, origem socioespacial ${ }^{3}$. Em outras palavras, a luta contra a intolerância religiosa está fortemente vinculada no mundo contemporâneo à afirmação da etnicidade e a processos identitários, especialmente da cultura afro-brasileira e suas práticas religiosas no que diz respeito ao Brasil.

Com essa direção podemos então pensar que é no processo de mão dupla de identidade/alteridade (ativado pelas afirmações étnicas e por processos identitários) que vamos assistir à emergência de questões da sociedade hodierna que expressam situações onde limites significados por uma diversidade de práticas culturais passam a ser traçados. São limites ou fronteiras culturais que apresentam, na cartografia contemporânea da sociedade, a 
emergência das culturas alternativas - sinalizado por Corrêa (2004) embasado em Cosgrove como aquelas que, ao se realizarem através de uma condição de subversão por grupos sociais (inseridos no processo de identidade/alteridade), estabelecem o contraponto com a cultura hegemônica e permitem, por sua vez, a delimitação de territórios que possuem no cerne de sua constituição ações embasadas pela prática cultural. Nas palavras de Bonnemaison (2002, p.105): “(...) Essa semiografia quadricula o espaço de territórios que são sociais e, mais profundamente culturais".

Retomando o sentido filosófico sobre o que define "luta" e assumindo que esta sinaliza o confronto de forças antagônicas que, em ultima instância, se localizam na figura "de um" e "do

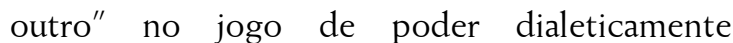
engendrado de identidade / alteridade e enfatizando mais uma vez as palavras de Yory (2007, p.92) para quem "ao fim das contas, mesmo quando na cidade temos mais de duas forças em conflito, estas se reduzem sempre a duas", passamos então a pensar e a buscar a compreensão de como a luta entre as religiões de matriz africana e os neopentecostais como territórios culturais antagônicos se apresenta na área sinalizada como foco de nossa atenção, lembrando que nesse processo distintas religiões, grupos étnicos e outros segmentos da sociedade que se veem subalternizados se aproximam das religiões de matriz africana
(Candomblé e Umbanda) e tecem alianças lutando, dessa forma, em conjunto contra a intolerância religiosa, o preconceito racial e ações homofóbicas, procedimentos atribuídos aos praticantes da religião neopentecostal que passam a ser identificados pela agressividade e por serem excludentes daqueles que não compartilham de suas diretrizes negando, dessa forma, os direitos constitucionais brasileiros.

\section{Intolerância e as religiões de matriz africana, agenciamentos para a Luta, instabilidade e competição, estratégias e territorialidades}

Até o momento estabelecemos, no presente texto, um pensamento no qual tratamos da prática cultural vinculada ao religioso de forma ampla sem especificar uma determinada prática. No entanto, ao localizar a discussão na cidade do Rio de Janeiro, passamos a observar que estratégias específicas, territorialidades para configuração de um território são engendradas por meio de agenciamentos coletivos de demandas cuja tônica reside na liberdade, garantia e promoção por meio de políticas públicas do direito de crença.

Apesar do movimento de repúdio à intolerância religiosa - que teve sua primeira manifestação no espaço público citadino brasileiro na Avenida Atlântica, em Copacabana (bairro emblemático do Rio de Janeiro), no dia 21 de setembro de 2008 e foi reconhecido 
como Caminhada em Defesa da Liberdade Religiosa - ter congregado distintos segmentos religiosos tais como mulçumanos, judeus, hareKrishnas, budistas, ciganos e índios ${ }^{4}$, ficou visível por meio das roupas brancas, guias coloridas (sinais da proteção dos orixás e de pertencimento às religiões afro-brasileiras) que a manifestação em questão foi e ainda é capitaneada pelas religiões de matriz africana como a Umbanda e o Candomblé.

Tal liderança se constituiu quando representantes - chefes religiosos, Iyalorixás, Babalorixás e Babalawôs - da Umbanda, do Candomblé e do Culto à Ifá respectivamente passam a se organizar como Movimento Social a partir da criação, em março de 2008, da Comissão de Combate à Intolerância Religiosa (CCIR) que possuiu como gatilho, na cidade do Rio de Janeiro, o caso que envolvia traficantes que se identificavam como "convertidos de Jesus" residentes na Ilha do Governador que atacaram o povo-de-santo e seus templos de Umbanda e terreiros de Candomblé, provocando a sua expulsão da área do bairro, evidenciando, assim, uma luta pelo espaço e traçando, dessa forma, limites que passam a semiografar um território dominado pelo narcotráfico e evidenciado pela demonstração de força na repressão à prática religiosa em tela (foto 01).

Noticiadas amplamente pela mídia ${ }^{5}$, as ações de violência sinalizadas acima, que foram consideradas pelos grupos religiosos vitimados como um verdadeiro "ataque" efetuado pelos neopetencostais, provocaram indignação e, portanto, a mobilização de candomblecistas e umbandistas no traçar de estratégias de Luta para enfrentamento da força religiosa antagônica.

O recurso de enfretamento buscou a parceria com o Estado como a manifestação pública na Assembleia Legislativa do Estado do Rio de Janeiro (ALERJ) objetivando, com a presença da CCIR, buscar os instrumentos legais com foco no cumprimento da Constituição no que concerne ao respeito à liberdade religiosa e ao combate ao preconceito religioso. A partir desse momento, novas estratégias/territorialidades passam a ser engendradas para a continuidade do movimento e para a semiografia de um território de fronteiras porosas constituídas pelos distintos segmentos religiosos que aderem à proposta do CCIR, no qual a circularidade de forças se torna a tônica para as ações de confronto e cooperação onde múltiplas territorialidades são tecidas e agenciadas entre si. Parcerias são estabelecidas com outras instituições públicas como o Tribunal Judiciário, Ministério Publico, Policia Civil RJ, Policia Militar, universidades como a UFF; UERJ; ONU; Secretarias municipais e estaduais e empresas estatais como a Petrobrás, o Metrô e a Supervia. 
Como exemplo dessas estratégias/territorialidades, podemos elencar: as Caminhadas ${ }^{6}$, o Fórum de Diálogo InterReligioso ${ }^{7}$, o Workshop para Delegados e detetives da Policia Civil, as reuniões para apresentação e análise de propostas para composição do Plano Nacional de Combate à Intolerância Religiosa, o DVD Ojuobá, lançado no dia 21 de janeiro de 2009, Dia Nacional de Combate à Intolerância Religiosa, instituído como homenagem à Iyalorixá soteropolitana Gilda de Ogum falecida em $2004{ }^{8}$; publicação do Guia de luta Contra a Intolerância Religiosa e o Racismo de autoria de Jorge da Silva pelo CEAP; 20 eventos para divulgação da Caminhada com exibição do Vídeo e distribuição do Guia foram promovidos por distintos templos Umbandistas e Terreiros de Candomblé em 12 bairros distribuídos entre a zona oeste, sul, centro e zona norte da cidade do Rio de Janeiro e em 09 municípios adjacentes à cidade em questão perfazendo um total de 13 eventos de acordo com o Relatório sobre a Comissão de Combate à Intolerância Religiosa elaborado pelo Instituto de Estudos Comparados em Administração Institucional de Conflitos (IECEIC )/NUFEP, da Universidade Federal Fluminense - UFF - para o ano de 2009.

De acordo com o relatório acima sinalizado, o movimento social contra a intolerância sob a perspectiva religiosa em tela se diferencia de outros movimentos em que estavam envolvidas distintas práticas religiosas, como o organizado pelo ISER no bojo das ações engendradas na Eco-92 (que promovia a intensificação de religiosos no enfrentamento à pobreza e à violência), por efetuar demandas de reconhecimento dos direitos de liberdade de credo junto ao poder público e por estar dentro da dinâmica contemporânea da valorização de processos identitários, ações que estão vinculadas - de acordo com nossa perspectiva a uma plêiade de mudanças culturais baseadas na igualdade do direito à diferença que colaboram para a constituição de territórios engendrados pelas ações materiais e imateriais fomentada pelas práticas culturais.

Nas palavras do Relatório efetuado pelo grupo de pesquisadores do campo do saber antropológico:

A agenda do enfrentamento à intolerância e de reconhecimento de direitos à liberdade religiosa a partir de demandas ao poder público, em especial, a policia e ao poder judiciário, representa um diferencial deste movimento social em relação ao Movimento Inter-Religioso do Rio de Janeiro, fundado em 1992 após a Vigília Inter-Religiosa pela Terra, organizado pelo ISER (IECEIC/NUFEP/UFF,2009). 
Nesse sentido, na semiografia do território cultural e as territorialidades do CCIR foram eficazes com estratégias que se valiam desde a criação da imagem de um mártir - a Iyalorixá Gilda de Ogum, que faleceu em 2004, ao ver sua foto estampada no Jornal da igreja Universal com a manchete acusando-a de ser macumbeira e de fazer charlatanice. Não resistiu à vergonha e ao enfarto - até a agenda de datas comemorativas utilizando a ação do rememorar a história e as estórias do povo-de-santo na cidade. Investiram na difusão do conhecimento com a criação do Guia facilitando, dessa forma, a comunicação e o acesso ao conhecimento dos direitos garantidos por Lei. Estabeleceram suas demandas e pressionaram o Estado em direção às Políticas Públicas, traçaram parceria com o governo de Estado por meio da Secretaria de Direitos Humanos e a Superintendência de Direitos Individuais, Coletivos e Difusos (SuperDir) e no presente ano, com a participação da Universidade do Estado do Rio de Janeiro (UERJ), elaboraram um programa de ações que intentam garantir atendimento psicológico, advocatício e uma central para denúncias sobre intolerância religiosa.

\section{Múltiplas territorialidades agenciadas no espaço público: A Caminhada Eu tenho Fé}

Nos primórdios da organização socioespacial das cidades, no período final da
Idade Média, as corporações de ofício significaram para os antigos servos, no momento em tela, homens livres, a estratégia para a reformulação de uma identidade que se construía e se fortalecia no dia-a-dia da vida citadina operada sob uma única lei: a competência do oficio e a associação na solidariedade com os seus iguais. Uma identidade que passa a consolidar uma estratificação social e que, vinculada à qualificação profissional, se exibe no espaço público da cidade nas comemorações dos santos protetores católicos, nas procissões que percorriam suas ruas, pois que, as corporações de ofício, conforme a atividade desempenhada possuíam cada qual seu santo de devoção, o seu padroeiro.

$$
\text { Essa estratificação social e a }
$$
demonstração de pertencimento e identidade corporativa eram sinalizadas nos trajes que os membros dessas corporações ostentavam nos eventos festivos e nas solenidades. Essas indumentárias possuíam marcas sígnicas que os destacavam como um grupo dos demais que se exibiam nos logradouros públicos no acontecimento das procissões solenes, onde o corpo do indivíduo atuava como suporte sígnico (CORRÊA, A. M., 2004), manifestando, no espaço da cidade através desta significação, "uma sólida consciência da linguagem como mediação, como representação da estrutura social" (FERRARA, 1990, p.4). Entretanto, uma estratificação social que ao ser marcada nos 
corpos e nas ações que os identificavam como grupo social ensejou o desenho da inauguração de um novo estilo de vida empreendido pelo antigo servo - agora homem livre e citadino contribuindo, então, para sua recomposição social operada através de ações estratégicas de sobrevivência, de proteção, de distinção identitária - territorialidades - que por sua vez, no rebatimento dessas no espaço livre da cidade, passam a dividi-la através de territorializações de fronteiras simbólicas significadas por meio das ações efetuadas pela nova identidade corporativa.

Dessa forma, os novos citadinos, pautados por uma distinção social significada na qualificação profissional, estabeleceram um novo eixo de atuação do poder (antes vivenciado sob a relação de servidão) cartografando no espaço da cidade nexos territorializados operados através de territorialidades - especialmente significada na dramatização do ritual propiciado pelo momento extraordinário - na qual a relação de identidade e singularidade emergia no cenário da cidade medieval como desejo e necessidade desse novo homem europeu. Tal condição das procissões católicas e a sua importância na representação e singularização dos grupos sociais são sinalizadas por Munford (1982, p.304) na descrição da solenidade comemorativa da Assunção de Nossa Senhora. Vejamos:
(...) No domingo depois da Assunção de Nossa querida Senhora, eu vi a grande procissão da Igreja de Nossa Senhora de Antuérpia, quando a cidade inteira, de todos os ofícios e de todas as condições, achava-se reunida, cada qual a usar as suas melhores roupas, conforme a sua posição. E todas as ordens e corporações ostentavam as suas insígnias, pelas quais podiam ser reconhecidas.(...) Vi a procissão passar ao longo da rua, o povo alinhado em fileiras muito próximas umas das outras. Estavam ali os Ourives, os Pintores, os Pedreiros, os Bordadores, os Escultores, os Marceneiros, os Carpinteiros, os Marinheiros, os Pescadores, os Alfaiates, os Sapateiros e enfim, trabalhadores de todas as espécies, e muitos artesãos e negociantes que trabalhavam para garantir a vida.

Com essa perspectiva de elaboração de identidade articuladas às ações de solidariedade entre seus membros, as Irmandades, associações de caráter religioso composta por leigos, emergiram assemelhando-se às Corporações de Oficio e tornando-se parte de um mesmo 
movimento confraternial que atinge seu ápice na Europa nos últimos séculos da Idade Média. Ambas as Instituições possuem no seu cerne o objetivo de contemplar a resolução das necessidades inerentes à cidade medieval caracterizado, por um lado, pelo assombro de moléstias e, por outro, pela articulação de sua imagem que se consolidava, como o lócus da liberdade, distinguindo-se uma associação da outra somente pelo eixo de atuação, todavia, conservando os mesmos propósitos.

Nos dias de hoje, no mundo globalizado, na cidade contemporânea o espaço da rua identificado como espaço público - de todos - ainda conserva o apelo da visibilidade, ou seja, a oportunidade de ver e ser visto, assim como do espaço próprio das festas coletivas, especialmente as religiosas com suas solenidades que usufruem desse atributo do espaço público para afirmar poderes e identidade.

Então, não poderia ser diferente para o movimento contra a intolerância religiosa na sua intenção de conseguir visibilidade pública e demonstrar a força de luta que trazia consigo. Foi para as ruas, melhor foi para a Av. Atlântica, no bairro de Copacabana (conhecida mundialmente por sua beleza, calçadas desenhadas e hotéis de alto luxo, como o Copacabana Palace, tornando este logradouro um lugar de referência, um geossímbolo ${ }^{9}$ para a cidade do Rio de Janeiro).
Entretanto, esse trajeto da caminhada capitaneada pelo povo-de-santo (assim identificados os adeptos das religiões de matriz africana - Candomblé e Umbanda) também não poderia ser em outro logradouro da cidade do Rio de Janeiro tendo em vista o significado que é atribuído a esse espaço da cidade pelos organizadores do movimento em questão.

O simbolismo e o significado de caminhar margeando toda a orla marítima do Leme ao Posto Seis torna-se, perante o Movimento contra a intolerância religiosa, uma territorialidade que, por intermédio do significado do mar, da praia - pois é o lugar onde Iemanjá mora, onde o orixá, a grande mãe de todas as cabeças (ori) é reverenciada e recebe seus presentes na forma de oferendas de seus filhos dedicados - semiografa no espaço público o território da paz, no qual a tolerância é vivenciada na cacofonia dos sons de tambores, chocalhos, violões, nas danças, nas indumentárias coloridas e significativas dos processos identitários dos grupos religiosos presentes. Na diversidade de abordagem dos discursos, porém, perseguindo o mesmo tema: paz, liberdade e respeito religioso. Nas rezas e nas advertências de que o sentido do movimento em tela é religioso, mas ao mesmo tempo é político posto que reivindicações são expostas publicamente pelas autoridades religiosas apoiadas por políticos presentes ${ }^{10}$. 
Nomear a manifestação como uma Caminhada também ganha importantes simbolismo e significado para a ação em questão e orienta o sentido da semiografia do território multicultural, de fronteiras porosas, no qual a diversidade de credo e de orientação sexual, a diferença das raças e das etnicidades se encontram dialogicamente na promoção da coexistência pacífica e da tolerância. Poderia ser uma Procissão, como é denominado o ato solene da Igreja Católica Romana, vivenciada historicamente no espaço público das cidades ocidentais, tendo em vista que a formação dos grupos religiosos obedecia à estética da organização católica e evocava permanentemente o sentido religioso ao afirmar "Eu tenho fé". Da mesma forma, poderia ser identificada com uma passeata política, comum também historicamente aos movimentos sociais como estratégia de reivindicação dos direitos civis, pois a mesma expressão - "Eu tenho Fé" afirmava ao longo do trajeto o direito à diferença de credo garantido pela Constituição Brasileira e dos processos identitários assumidos pelos distintos grupos étnicos ali presentes para reivindicar seus direitos de cidadãos e de respeito na sua existência cotidiana no espaço da cidade. Significava, assim, um não ao racismo, um não à discriminação e um sim à diferença e à diversidade cultural.

No entanto, foi/ é uma caminhada. Tranquila na sua efervescência, festiva e solene, religiosa e política. Diversa e única. Agenciadora de múltiplas subjetividades. Contemporânea.

\section{Concluindo}

O tema objeto do presente texto não se esgota aqui tendo em vista que estamos observando analiticamente um movimento cultural que é também social posto que as práticas culturais são práticas sociais e, por esse motivo, estão em permanente mutação como fruto dos embates, das alianças, dos múltiplos sentidos e agenciamentos. Vale ressaltar que no ano de 2010 ocorreu a III Caminhada contra a Intolerância Religiosa e transformações no sentido inicial foram observadas fazendo com que novas tensões sejam então incorporadas ao Movimento em tela. Todavia, deixaremos para mais adiante a reflexão sobre a questão.

O sagrado pertence aos deuses e cabe aos homens promover permanentemente em suas crenças o ponto de equilíbrio do respeito à diferença do professar religioso tecendo suas alianças estratégicas como reivindicar o apoio das leis e de políticas públicas como garantia da civilidade vivenciada no espaço da cidade cotidianamente complexo na contemporaneidade. $\mathrm{O}$ desafio está posto. Oxalá seja este o caminho.

\section{Notas}


1 Profa. Dra. Instituto de Geografia/Departamento de Geografia Humana - Universidade do Estado do Rio de Janeiro.

${ }^{2}(\ldots)$ pues, a fin de cuentas, aún cuando em la ciudad hay más de dos fuerzas emconflito, estas se reducem siempre a dos (YORY,Carlos Mario,2007,p.92)

${ }^{3}$ Intolerância, então, manifesta-se sob as formas de discriminação racista, homofóbica, machista, xenofóbica e do que denominamos como estigmas do lugar, fomentados pelo local de moradia do indivíduo na cidade - favelado/traficante/malandro/pobre. Resumindo toda e qualquer atitude autoritária por parte do indivíduo ou grupo em relação a outro indivíduo ou grupo considerados pelos primeiros como culturalmente inferiores e, portanto, diferentes.

${ }^{4} \mathrm{~A}$ I Caminhada segundo os seus organizadores (CCIR) reuniu por volta de 20 mil pessoas

${ }^{5}$ O Jornal Extra (RJ) publicou, em 15/03/2008, uma reportagem efetuada pela repórter Adriana Diniz sob a manchete intitulada BANDIDOS PROÍBEM MANIFESTAÇÕES DE UMBANDA, CANDOMBLÉ E EXPULSAM DONOS DE TERREIROS DOS MORROS. A matéria versava sobre a expansão das igrejas independentes nas comunidades, seus líderes se intitulavamm pastores e exigiam pouco da conversão: os bandidos podiam continuar no crime e podiam ostentar o título de convertidos de Jesus, em troca expulsavam a concorrência de seus territórios. Os traficantes efetuavam duas formas de ação: expulsão sumária dos umbandistas e cadomblecistas ou imposição de normas que impediam a prática religiosa. No dia 19/03/2008, uma operação policial foi feita no Morro do Dendê (Ilha do Governador) e um soldado do tráfico foi preso e confirmou que o chefe local, o traficante Fernando Gomes de Freitas, tinha mandado fechar todos os terreiros e proibido qualquer manifestação de Umbanda ou de Candomblé na comunidade (Jorna Alerj 169).

${ }^{6}$ No presente ano, 2010, foi empreendida a terceira caminhada que ocorre e deve buscar ocorrer sempre no mês de setembro por determinação de Ifá (segundo o Babalawô Ivanir dos Santos, presidente da ONG Centro de Articulação de Populações Populares Marginalizadas e um dos fundadores do CCIR). Ifá é um sistema divinatório que fornece orientação para a resolução dos problemas e, segundo VERGER (2002, p. 97), "as soluções lhe são ditadas pelos signos (odú) de Ifá, obtidos pela manipulação, que obedecem a certas regras, de nozes de dendezeiro (Elaeis guineenses var. idolátrica) Existem ao todo duzentos e cinquenta e seis odús. Cada pessoa depende de um deles. "Este sistema divinatório é a voz de Deus, que encerra o homem em seu determinismo" (VERGER, ibid) e acrescentamos que também as divindades. Sendo assim, Ifá é a base filosófica, religiosa e ética que conduz a sociedade iorubana no cotidiano da vida no Ayiê e no Orum como também no Brasil aos Cadomblecistas.

7 O Fórum - de acordo com a forma pela qual se identifica - é um espaço aberto de encontro entre seus membros e a sociedade como um todo para o aprofundamento da reflexão, o debate democrático de ideias, a formulação de propostas sobre diferentes abordagens religiosas identificadas e comprometidas com as práticas de liberdade, resistência e transformação ( Anexo 01)

${ }^{8} 21$ de janeiro Dia Nacional de Combate à Intolerância Religiosa. Promulgado por meio da Lei Federal 11.635/2007, objetiva a constituição da reflexão sobre as distintas visões sobre todo tipo de intolerância e discriminação em especial a religiosa em todo o território brasileiro.

${ }^{9}$ Como já assinalamos em textos anteriores (CORRÊA, A. M, 2004; 2010 entre outros da autora), embasada em Bonnmaison (2002), o geossímbolo pode ser um lugar, um itinerário, uma extensão que por distintas razões, ou seja, religiosas, políticas, culturais ou afetivas, aos olhos de certas pessoas e/ou grupos - étnico, de gênero entre outros assume uma dimensão simbólica que passa a fortalecer seus processos identitários.

${ }^{10}$ Na I Caminhada (20/09/2008), entre tantos políticos destacamos a presença do deputado estadual Carlos Minc, do governador do Estado do Rio de Janeiro Sérgio Cabral, do deputado federal Crivela (pastor evangélico) e do deputado federal Gabeira, expressando assim, além da diversidade religiosa, a diversidade de orientação política.

\section{REFERÊNCIAS BIBLIOGRÁFICAS}

BONNEMAISON, J. Viagem em torno do território. In: CORREA; ROSENDAHL (org.). Geografia Cultural: um século (3), Rio de Janeiro: Eduerj, 2002.

CORRÊA, A. M. Irmandade da Boa Morte como manifestação cultural afro-brasileira: de cultura alternativa à inserção global. Tese de Doutorado. Rio de Janeiro: CCMN / PPGG/UFRJ, 2004

Irmandade da Boa Morte - resistência subjetiva frente ao sistema mundo. In: DEMBICZ (coord.) El Espacio en la Cultura Latino Americana. Varsóvia: Centro de Estúdios LatinoAmericanos (CESLA), 1997

FERRARA, L. As máscaras da cidade, São Paulo, Revista USP, n.5, 1990.

MUNFORD, L. A cidade na história. vol. II ; Belo Horizonte: Itatiaia, 1982.

MULLER, M. A religião sem Razão. Revista Filosofia, ano IV, n.4, São Paulo: Escala, 2009.

RELATÓRIO SOBRE A COMISSÃO DE COMBATE À INTOLERÂNCIA RELIGIOSA. Niterói: Instituto de Estudos Comparados em Administração Institucional de Conflitos (IECEIC /NUFEP), Universidade federal Fluminense - UFF, para o ano de 2009.

ESPAÇO E CULTURA, UERJ, RJ, N. 31, P.125-138, JAN./JUN. DE 2012 http://www.e-publicacoes.uerj.br/index.php/espacoecultura/ 
SENNETT, R. Carne e pedra. O corpo e a cidade na civilização ocidental. Rio de Janeiro: Record, 1997.

SOPHER, D. Geography of religions. Englwood Cliffs, Prentice

Hall Inc.. 1967.

VERGER, P. Saída de Iaô. São Paulo: AxisMundi, 2002

VOLTAIRE. Tratado sobre a tolerância. São Paulo: Martins Fontes, 2005

Dicionário Filosófico, Os pensadores. São Paulo: Abril

Cultural, 1973

YORI, C. M., Ciudad y Posmodernidad. Bogotá: Universidad Piloto de Colômbia, 2007.
Sites

CEAP. Guia de Luta Contra a Intolerância Religiosa e o Racismo, 2009 .

EXTRA. Jornal, Rio de Janeiro. Bandidos proíbem manifestações de umbanda, candomblé e expulsam donos de terreiros dos morros. Adrana Diniz.15/03/2008.

Jornal ALERJ n.169.

VOLTAIRE. Ouvres Complètes. Tomes deuxième.Essai sur lês mouers -siècle de Louis XIV, siècle de Louis XV, Histoire du Parlement du Paris. Edition du Journal Lê Siècle. Paris. Aux Bureau du Siècle, $1878 . \quad$ Disponível em: http://perso.wanadoo.fr./dboudin/VOLTAIRE/36/1742/1505

THE SACRED IS DIVINE, THE RELIGION BELONGS UNDER THE MEN : CULTURAL TERRITORIES AND SYMBOLIC FRONTIERS, THE RELIGIOUS INTOLERANCE IN CONTEMPORARY

Abstract : This paper aims to present an initial reflection on the social movement created in the city of Rio de Janeiro in 2008 as a reaction to actions of religious intolerance. These actions occurred (and still occur) establishing two opposite forces: on one hand we have evangelicals, one the other, different religions, such as Muslims, Jews, Catholics, Harekrishnas, and Gypsies under the leadership of Candomblecistas and Umbandistas. This social movement claims for city space in order to guarantee the freedom to profess their faith and ensure the compliance of the Brazilian Constitution, semiographing with strategies/territorialities collectively engendered in cultural territories at the contemporary city. 
Keywords: religious intolerance, social movement, territorialities

ESPAÇO E CULTURA, UERJ, RJ, N. 31, P.125-138, JAN./JUN. DE 2012 http://www.e-publicacoes.uerj.br/index.php/espacoecultura/ 